\title{
Novel Simplified Analytical Method for Stress Degradation Study of Empagliflozin an Oral Anti-diabetic Agent by RP-HPLC Method
}

\section{Arulselvan Murugesan ${ }^{1 *}$ and Annapurna Mukthinuthalapati Mathrusri $^{2}$}

${ }^{1}$ Department of Pharmaceutical Analysis, AIKTC School of Pharmacy, New Panvel Dist-Raigad (M.S.), India

${ }^{2}$ Department of Pharmaceutical Analysis and Quality Assurance, GITAM Institute of Pharmacy, GITAM (Deemed to be University), Visakhapatnam, India

*Corresponding Author: Arulselvan Murugesan, Department of Pharmaceutical

Analysis, AIKTC School of Pharmacy, New Panvel Dist-Raigad (M.S.), India.
Received: September 21, 2021

Published: December 09, 2021

(C) All rights are reserved by Arulselvan

Murugesan and Annapurna

Mukthinuthalapati Mathrusri.

\begin{abstract}
The present study involved developing novel, simplified analytical methods for estimating Empagliflozin in API and finished formulation as per the guidelines of ICH. Meanwhile the study focused on conducting forced degradation studies for Empagliflozin to identify the degraded products and its percentage. The applied chromatographic separation method as follows RP-HPLC ZORBAxC18 ( $250 \times 4.6 \mathrm{~mm}, 5 \mu \mathrm{m}$ particle size) with a mobile phase consisting of Acetate buffer: Acetonitrile in a ratio of $60: 40 \% \mathrm{v} / \mathrm{v}$ at a flow rate of $1.0 \mathrm{~mL} / \mathrm{min}$ with an injection volume of $10 \mu \mathrm{l}$ with 6 minutes run time. The Retention time of Empagliflozin was found to be 2.57 $\pm 0.05 \mathrm{~min}$ and detected at $232 \mathrm{~nm}$ UV wavelength. The method was found to be linear based on the Linear regression equation $\mathrm{y}=$ 61309 x- 8123 with correlation coefficient 0.9999 . Validation parameters performed as per the prescribed protocol. Stress degradation experiments were performed by exposing the Empagliflozin into acidic, alkaline, oxidative, thermal, and photolytic conditions, withdrawing samples at different time intervals and injected into the system as per ICH guidelines to analyze the drug. The developed method was novel, precise, simple, and accurate with low consumption of organic solvents to estimate Empagliflozin in API and bulk formulation compared to previously reported studies.
\end{abstract}

Keywords: Empagliflozin; Stress degradation; Validation; ICH; Forced stability; SGLT2; RP-HPL

\section{Introduction}

Empagliflozin (EMP) gliflozin derivative, chemically called as (2S, 3R, 4R, 5S, 6R) -2- [4-chloro -3- [[4-[(3S)-oxolan-3-yl] oxy phenyl] methyl] phenyl]-6-(hydroxy methyl) oxane-3, 4, 5-triol [1]. Empagliflozin by its independent hypoglycemic mechanism protects the diabetic patients suffering with cardiac and kidney disorder. The structure of Empagliflozin is shown in figure 1.
As per 2017 report $6.28 \%$ largest number of the population suffered from Type 2 Diabetic mellitus which is a life threatening and cause remarkable changes in social and health care systems. Treating patients suffering with Type 2 diabetes mellitus need drug therapy with changes in lifestyle pattern like proper diet, exercise, and prescribed lifestyle [1].

In T2DM drug therapy treating patients with SGLT found to be recurrent and positive. Gliflozin derivatives reduce the glucose 


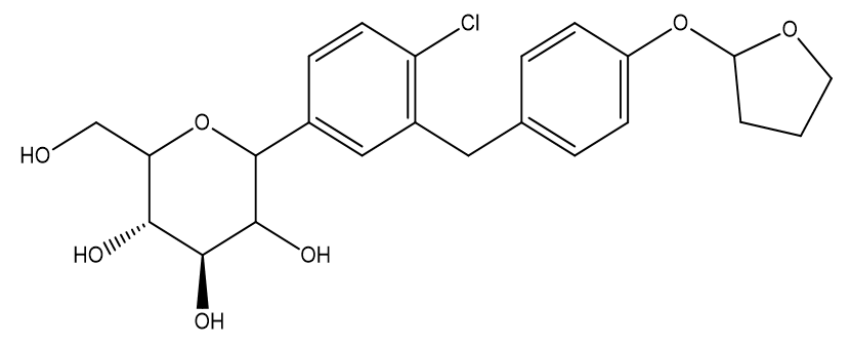

Figure 1: Structure of Empagliflozin.

reabsorption by kidney and improve urinary excretion of glucose thereby reducing the blood glucose level in patients suffering with Type 2 diabetic mellitus. In diabetic type 2 blood glucose level is found more and it is due to $90 \%$ absorption of glucose by SGLT, inhibiting them by gliflozin reduces the level which was highly recommended therapy nowadays. Empagliflozin by its independent hypoglycemic mechanism protects the diabetic patients suffering with cardiac and kidney disorder [2-4].

Empagliflozin was assayed by various methods and only a very limited number of single component analyses by HPLC [5-8] published by the researchers. Many combination reports of Empagliflozin with Metformin [9-11] and Linagliptin [12-15] analyzed by HPLC by utilizing various organic mobile phases. Other spectroscopic methods [16-18] adapted to assay by UV/Visible spectroscopy [19-22] and bioanalytical process [23, 24].

\section{Materials and Methods}

\section{Chemicals and reagent}

HPLC grade Acetonitrile, Sodium Acetate HPLC grade of Rankem Limited, India, HPLC grade water of SD fine-Chem Itd; Mumbai and Glacial Acetic acid HPLC grade Loba chemie Pvt Ltd; Mumbai procured to perform our research work. Empagliflozin API received as a gift sample from Supriya Life science Ltd, India. Jardiance $10 \mathrm{mg}$ film coated tablets of Empagliflozin purchased from a local chemist shop.

\section{Instrumentation}

For this study, HPLC system Shimadzu 2010CHT with a gradient pump connected to a UV detector, ZorbaxC18 column was used.
The cumulative Data acquired from Lab solution software (5.5.2 Version). An electronic analytical weighing balance Shimadzu 0.001gm sensitive and an Equibtron Ultra-sonicator were used in this entire study with I-Therm dry air oven, UV Chamber was utilized to conduct forced degradation studies of Empagliflozin in API and bulk formulation.

Chromatographic parameters

Equipment: SHIMADZU 2010CHT HPLC System

Wavelength: $232 \mathrm{~nm}$

Injection volume $: 10 \mu \mathrm{L}$.

Flow rate: $01 \mathrm{~mL} / \mathrm{minute}$.

Run time: 6 Minutes.

Column : ZORBAxC $_{18}(250 \times 4.6 \mathrm{~mm}, 5 \mu \mathrm{m}$ particle size $)$

Mobile Phase: Acetate buffer (pH 3.4): Acetonitrile (60:40)

Oven Temperature: $28^{\circ} \mathrm{C}$.

Preparation of sodium acetate buffer solution (pH 3.4)

Measured and dissolved $28.6 \mathrm{ml}$ glacial acetic acid with $10 \mathrm{ml}$ of $50 \%(\mathrm{w} / \mathrm{v}) \mathrm{NaOH}$ in a $1000 \mathrm{ml}$ volumetric flask, mixed it properly and made the volume with HPLC grade water.

\section{Preparation of stock solution}

Accurately weighed and transferred $10 \mathrm{mg}$ of Empagliflozin into $10 \mathrm{ml}$ volumetric flask. Dissolved and mixed it properly then made the volume with diluent. Diluent is the solvent used as a mobile phase in this experiment. Final concentration of the Stock solution is $1000 \mu \mathrm{g} / \mathrm{ml}$.

\section{Method validation}

Method validation parameters carried out for Empagliflozin as follows: Precision, Accuracy, Specificity, Linearity, Precision and Robustness as per guidelines of ICH Q2A and Q2B.

For Linearity, the series of solutions over the range of 10, 20, 30, 40, 50, 60, 100 and $120 \mu \mathrm{g} / \mathrm{ml}$ of Empagliflozin prepared in triplicate by diluting stock solution in mobile phase and injected into the HPLC system. Linearity graph was plotted by taking the 
concentration on the $\mathrm{x}$-axis against the corresponding peak area on the y-axis.

Intra and Interday Precision were performed with $5 \mu \mathrm{g} / \mathrm{ml}, 10$ $\mu \mathrm{g} / \mathrm{ml}$, and $15 \mu \mathrm{g} / \mathrm{ml}$ concentration of Empagliflozin. Replicates of 3 injections with $5 \mu \mathrm{g} / \mathrm{ml}, 10 \mu \mathrm{g} / \mathrm{ml}$ and $15 \mu \mathrm{g} / \mathrm{ml}$ concentration injected into the HPLC system and its retention time, peak area were calculated for assuring its method precision.

Recovery studies conducted for Empagliflozin by adding $8 \mu \mathrm{g} /$ $\mathrm{ml}, 10 \mu \mathrm{g} / \mathrm{ml}$ and $12 \mu \mathrm{g} / \mathrm{ml}$ samples into sample solution with known concentration $10 \mu \mathrm{g} / \mathrm{ml}$. Addition of $8 \mu \mathrm{g} / \mathrm{ml}, 10 \mu \mathrm{g} / \mathrm{ml}$ and $12 \mu \mathrm{g} / \mathrm{ml}$ with $10 \mu \mathrm{g} / \mathrm{ml}$ sample stock solution gives $80 \%, 100 \%$ and $120 \%$ solution.

Robustness studies conducted by applying modified slight changes in the method parameters such as flow rate $( \pm 0.2 \mathrm{ml} /$ $\min )$, temperature $( \pm 2 \%)$ and mobile phase $( \pm 2 \%)$.

\section{Stress degradation studies}

Drug stability of Empagliflozin in stressed conditions is studied as per the guidelines of ICH by exposing it into various stress conditions such as acidic, alkali, oxidative, Thermal and Photolytic conditions. All solutions utilized for this study were diluted from the stock solution of $1000 \mu \mathrm{g} / \mathrm{ml}$ as per requirements.

\section{Acidic degradation}

Untreated samples of Empagliflozin solution withdrawn from sample stock solutions $1000 \mu \mathrm{g} / \mathrm{ml}$. Reflux the solution for 1 hour in a thermostat maintained at $80^{\circ} \mathrm{C}$. After 1hour, withdraw the solution cool and neutralize it with $0.1 \mathrm{~N} \mathrm{NaOH}$.

\section{Alkali degradation}

$100 \mu \mathrm{g} / \mathrm{ml}$ of sample stock solution refluxed in $80^{\circ} \mathrm{C}$ thermostat condition. After refluxing, the solution cooled and neutralized with $9 \mathrm{ml}$ of $0.1 \mathrm{~N} \mathrm{HCl} .10 \mu \mathrm{g} / \mathrm{ml}$ sample solution injected into HPLC system.

\section{Oxidation}

$10 \mathrm{ml}$ of stock solution transferred into a $250 \mathrm{ml}$ round bottom flask and added $90 \mathrm{ml}$ of oxidative agent $30 \% \mathrm{H}_{2} \mathrm{O}_{2}$. Allow the reaction to proceed for 2 hours at high temperature $\left(80^{\circ} \mathrm{C}\right)$ for at least $2 \mathrm{hrs}$ with continuous shaking.
Irradiation with ultraviolet light

The powder sample of Empagliflozin spread uniformly as exposed into UV light ( $254 \mathrm{~nm}$ ) for 2 days on a neat and clean surface. Dilute and inject the $10 \mu \mathrm{l}$ sample solution after exposure into the HPLC system.

\section{Thermal degradation}

The powder sample of Empagliflozin $(0.1 \mathrm{mg} / \mathrm{ml})$ was exposed to a temperature of $80^{\circ} \mathrm{C}$ for $48 \mathrm{hrs}$, a diluted sample of $10 \mu \mathrm{l}$ was injected into the HPLC system after exposure to measure peak height, area and retention time.

\section{Assay of marketed formulation (Tablets)}

Weighed and transferred 100 mg equivalent Empagliflozin tablet powder, triturated and dissolved it in $100 \mathrm{ml}$ solvent system. Filtered using $0.45 \mu \mathrm{m}$ syringe filter and injected $10 \mu \mathrm{g} / \mathrm{ml}$ equivalent sample solution into HPLC system to measure its Retention time and peak area.

\section{Results and Discussion}

Simplified method designed to estimate this weakly ionizable Empagliflozin drug, adopting the right method after various trials using different mobile phase composition, column, column temperature, flow rate and $\mathrm{pH}$ of solvent system ensured that the weakly ionizable drug is very sensitive towards its $\mathrm{pH}$.

The method was developed by varying different chromatographic conditions such as detecting wavelength, mobile phase composition, and polarity of mobile phase, temperature, column, and injection volume to obtain shorter retention time and good separation.

Various solvents such as Acetonitrile, Methanol, HPLC grade water and buffers of phosphate, Acetate were used in different ratios to determine the right mobile composition. The mobile phase Acetate buffer pH 3.4 with Acetonitrile eluted the drug within 3 minutes and it consumed very low organic solvent compared to reported methods [5-8]. Improved tailing factor observed with mobile phase acetate buffer with Acetonitrile (60:40\% v/v).

The proposed method showed high linearity in its peak area with concentration range of $10-120 \mu \mathrm{g} / \mathrm{ml}$. The linearity results were confirmed by its value $y=61039 x-8123\left(r^{2}=0.9999\right)$. Re- 
covery results were found to be more accurate $(99.55 \%, 99.08 \%$, 98.41\%), No deliberate variations observed in the results obtained in deliberate variation method (\% RSD less than 02), \% RSD for Intra-day and Inter-day precision was found to be more precise (0.25 to 0.34$)$.

Stress degradation methods used to study the specificity of the developed method for Empagliflozin in solution and solid-state form. Solution state method involved in analyzing the analyte in solution form such as Acid, Alkaline and oxidative condition, whereas solid method involved in analyzing the drug in solid form such as Thermal and Photolytic condition. Oxidative degradation, small reduction in peak area observed indicates possible degradation compared to Acidic, Alkaline, Thermal and Photolytic conditions figure 4.

Results of various analytical validating parameters found promising and precise for our entire experimental procedure as per ICH criteria $[25,26]$. The peak area and value obtained for various analytical methods experimented for Empagliflozin was summarized below in Hierarchy.

The chromatogram of Blank, Sample and Standard Empagliflozin summarized in figure 2 .

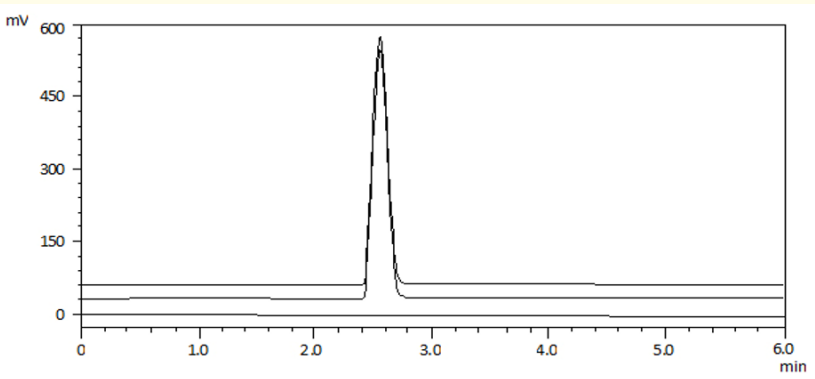

Figure 2: Chromatogram of Empagliflozin A-Blank, B-Standard, C-Sample in Optimized Condition.

\section{Method validation}

\section{Linearity}

The calibration curve was found to be linear for Empagliflozin with concentration range 10 to $120 \mu \mathrm{g} / \mathrm{ml}$. The correlation coefficient of regression value, concentration and intercept value figure.
3 , was calculated using the formula $y=61039 x-8123\left(r^{2}=0.9999\right)$ respectively and summarized in table 1 .

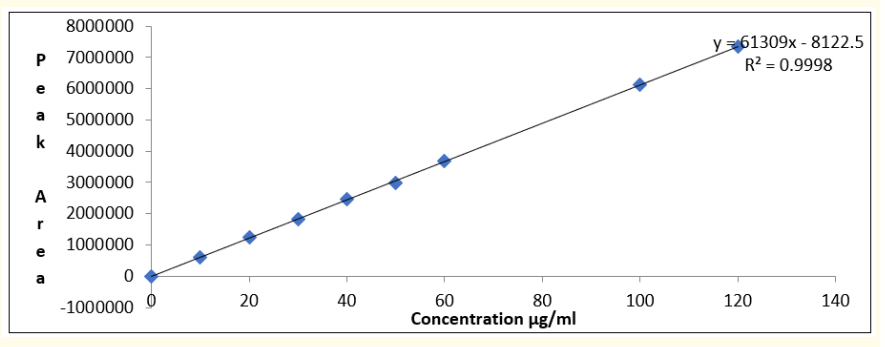

Figure 3: Calibration Curve of Empagliflozin.

\begin{tabular}{|c|c|c|c|c|}
\hline $\begin{array}{c}\text { S. } \\
\text { No }\end{array}$ & Injection no & RT & $\begin{array}{c}\text { Concentration } \\
(\boldsymbol{\mu g} / \mathbf{m l})\end{array}$ & $\begin{array}{c}* \text { Mean Peak } \\
\text { area }\end{array}$ \\
\hline 1 & Injection 1 & 0 & 0 & 0 \\
\hline 2 & Injection 2 & 2.57 & 10 & 613832 \\
\hline 3 & Injection 3 & 2.57 & 20 & 1235638 \\
\hline 4 & Injection 4 & 2.57 & 30 & 1826487 \\
\hline 5 & Injection 5 & 2.58 & 40 & 2452463 \\
\hline 6 & Injection 6 & 2.58 & 50 & 2977747 \\
\hline 7 & Injection 7 & 2.58 & 60 & 3694700 \\
\hline 8 & Injection 8 & 2.57 & 100 & 6131007 \\
\hline 9 & Injection 9 & 2.58 & 120 & 7357830 \\
\hline & & & Slope & 61309 \\
\hline & & & Intercept & -8122.450829 \\
\hline & & & $\begin{array}{c}\text { Coefficient Cor- } \\
\text { relation value }\end{array}$ & 0.9999 \\
\hline
\end{tabular}

Table 1: Linearity Results.

* Mean of three replicates.

\section{Accuracy}

The \% Mean recovery for Empagliflozin is 99.55, 99.08 and 98.41 for $80 \%, 100 \%$ and $120 \%$ and these results are within acceptable limits of Empagliflozin 98-102. The \% RSD for Empagliflozin was $0.43,0.57$ and 0.45 is within limit of $\leq 2$ and its high value of recoveries at $80 \%, 100 \%$ and $120 \%$ concentrations indicate the performed method is accurate. The accuracy data of the proposed method is summarized in table $2 \mathrm{~A}$. 


\begin{tabular}{|c|c|c|c|c|c|}
\hline Drug & $\begin{array}{c}\text { Spiked Conc } \\
(\mu \mathrm{g} / \mathbf{m l})\end{array}$ & $\begin{array}{c}\text { Total Conc } \\
(\mu \mathrm{g} / \mathbf{m l})\end{array}$ & *Mean peak area \pm SD (\%RSD) & Drug found & \% Recovery \\
\hline \multirow{2}{*}{ Empagliflozin } & $8(80 \%)$ & 18 & $1099971.33 \pm 4775.08(0.43)$ & 17.92 & 99.55 \\
\cline { 2 - 7 } & $10(100 \%)$ & 20 & $1216401 \pm 6937.52(0.57)$ & 19.82 & 99.08 \\
\cline { 2 - 7 } & $12(120 \%)$ & 22 & $1328985.33 \pm 6009.46(0.45)$ & 21.65 & 98.41 \\
\hline
\end{tabular}

Table 2A: Recovery studies values of Empagliflozin.

*Mean of three replicates.

\begin{tabular}{|c|c|c|c|c|c|}
\hline \multirow{2}{*}{ Drug } & Concentration & \multicolumn{2}{|c|}{ Intra-day } & \multicolumn{2}{|c|}{ Inter-day } \\
\cline { 2 - 6 } & $(\mu \mathrm{g} / \mathbf{m l})$ & *Mean peak area $\mathbf{~ S D}$ & \% RSD & *Mean peak area \pm SD & \% RSD \\
\hline \multirow{2}{*}{ Empagliflozin } & 5 & $217594 \pm 747.14$ & 0.34 & $218970 \pm 544$ & 0.25 \\
\cline { 2 - 7 } & 10 & $613159 \pm 2025$ & 0.33 & $611914 \pm 1735$ & 0.28 \\
\cline { 2 - 7 } & 15 & $823856 \pm 2026.11$ & 0.25 & $825106 \pm 2186.40$ & 0.26 \\
\hline
\end{tabular}

Table 2B: Intermediate and Method Precision studies of Empagliflozin.

*Mean of three replicates.

\section{Precision}

Intra-day Precision and Inter-day precision of Empagliflozin calculated by injecting 5, 10 and $15 \mu \mathrm{g} / \mathrm{ml}$ samples of three replicates into HPLC system, it was found to be more precise. The \% RSD of both the methods was found 0.25 to 0.34 and 0.25 to 0.28 indicates that the method was precise and reproducible.

\section{Robustness}

Deliberate changes in validation parameters didn't alter the robustness of the developed method. Robustness value for different parameters like Flow rate, Temperature and Mobile phase were summarized in table 3 . The $\%$ RSD was found to be less than $02 \%$ for Empagliflozin and no significant changes in the entire procedure which indicates the method is Robust.

Analysis of marketed formulation

The percentage purity of the six replicate samples found to be within the limit and the amount recovered for the assay method found to be $9.94 \mathrm{mg}$ and \% purity is 99.37. Reported \% purity of Empagliflozin found within the limit as per pharmacopeia.

\begin{tabular}{|c|c|c|c|}
\hline S. No & Parameters & Condition & *Mean peak area \pm SD (\%RSD) \\
\hline 1 & Flow rate & $(0.8 \mathrm{ml} / \mathrm{min})$ & \\
\hline 2 & Flow rate & $(1.0 \mathrm{ml} / \mathrm{min})$ & \\
\hline 3 & Flow rate & $(1.2 \mathrm{ml} / \mathrm{min})$ & $6139613(1.13)$ \\
\hline 4 & Mobile phase & $(58: 42)$ & \\
\hline 5 & Mobile phase & $(60: 40)$ & \multirow{2}{*}{$608960 \pm 5371(0.88)$} \\
\hline 6 & Mobile phase & $(62: 38)$ & \\
\hline 7 & Temperature & $26^{\circ} \mathrm{C}$ & \\
\hline 8 & Temperature & $28^{\circ} \mathrm{C}$ & \\
\hline 9 & Temperature & $30^{\circ} \mathrm{C}$ & \\
\hline
\end{tabular}

Table 3: Result of robustness method.

*Mean of three replicates. 


\begin{tabular}{|c|c|c|c|}
\hline Formulation & $\begin{array}{c}\text { Labeled } \\
\text { claim (mg) }\end{array}$ & $\begin{array}{c}\text { Amount } \\
\text { found } * \mathbf{m g})\end{array}$ & $\begin{array}{c}\text { Recovery } \\
\text { * (\%) }\end{array}$ \\
\hline Brand 1 & 10 & 9.94 & 99.37 \\
\hline
\end{tabular}

Table 4: Assay estimation of Empagliflozin.

* Mean of Six replicates.

Stress degradation studies

Stress degradation studies conducted as per the ICH guidelines and the drug Empagliflozin doesn't degrade in acidic, thermal, and photolytic method whereas the drug degrades in presence of basic and oxidative hydrolysis process figure 4. Amount of degraded drug products recovered in acidic, basic, oxidative, Thermal and Photolytic conditions $(0.84 \%, 2.73 \%, 5.05 \%, 1.44 \%$ and $0.93 \%$ ) summarized and reported in table 5 .

\begin{tabular}{|c|c|c|c|}
\hline Stress Condition & $\begin{array}{c}* \text { Mean } \\
\text { peak area }\end{array}$ & $\begin{array}{c}\text { Drug re- } \\
\text { covered } \\
\text { (\%) }\end{array}$ & $\begin{array}{c}\text { Drug de- } \\
\text { composed } \\
\text { (\%) }\end{array}$ \\
\hline $\begin{array}{c}\text { Standard drug (un- } \\
\text { treated) }\end{array}$ & 613872 & 100 & - \\
\hline Acidic degradation & 608741 & 99.16 & 0.84 \\
\hline Alkaline degradation & 597100 & 97.27 & 2.73 \\
\hline Oxidative degradation & 582856 & 94.95 & 5.05 \\
\hline Thermal degradation & 605037 & 98.56 & 1.44 \\
\hline Photolytic degradation & 608170 & 99.07 & 0.93 \\
\hline
\end{tabular}

Table 5: Data of Stress degradation studies Empagliflozin.

* Mean of three replicates.

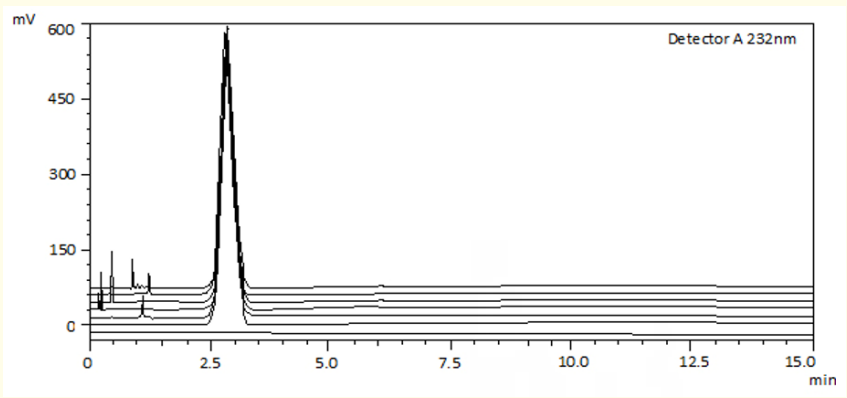

Figure 5: Chromatogram of Empagliflozin in Photolytic degradation A- Blank, B-Standard, C-Acidic, D-Alkaline, E-Oxidative, F- Thermal, G-Photolytic degradation.

\section{Conclusion}

This research work found promising in all parameters in eluting the analyte in less time by consuming low organic solvents. Intraday precision and Interday precision \% RSD values indicates the designed method has less than $2 \%$ RSD value without any significant variable changes. In Linearity regression method the peak area increases with the increasing concentration of sample. Our method can perform estimation of Empagliflozin in different laboratory conditions. Degradation studies practically proved that weakly ionizable flozin derivatives can also alter its nature in stress conditions such as basic and oxidative conditions. Altering forced degradation studies may be useful in identifying the various degraded products and can be analyzed by the LCMS method. This simplified method consumes less organic solvent and at the same time it elutes the analyte within a short period of time.

\section{Acknowledgment}

The authors felt grateful and happy the way we received support from Anjuman-I-Islam Kalsekar Technical Campus School of Pharmacy allowing us to conduct the research work in their Central Instrument Room (CIR) facility.

\section{Conflict of Interest}

Author declares No conflict of interest for this research work.

\section{Bibliography}

1. Harsharan PS., et al. "Sodium Glucose Co-Transporters-2 (SGLT2) Inhibitors as a New Class of Anti-diabetic Drugs: Pharmacokinetics, Efficacy and Clinical Significance". International Journal of Pharmaceutical Science Review and Research 33.1 (2015): 40-47.

2. Misra M. "SGLT2 inhibitors: a promising new therapeutic option for treatment of type 2 diabetes mellitus". Journal of Pharmacy and Pharmacology 65.3 (2013): 317-327.

3. Nair S and Wilding JP. "Sodium glucose co-transporter 2 inhibitors as a new treatment for diabetes mellitus". Journal of Clinical Endocrinology and Metabolism 95.1 (2010): 34-42.

4. Wright EM and Turk E. "The sodium/glucose co-transport family SLC5". Pflügers Archiv 447.5 (2014): 510-518. 
5. N Padmaja and G Veerabhadram. "Development and Validation of a Novel Stability-Indicating RP-HPLC Method for the determination of Empagliflozin in Bulk and Pharmaceutical Dosage Form". International Journal of Pharmaceutical Science and Research 7.11 (2016): 4523-4530.

6. Mounika P Siridevi., et al. "RP-HPLC Method for Quantification of Empagliflozin in Pharmaceutical Formulation". Asian Journal of Pharmaceutical Technology 9.3 (2019): 208-211.

7. Madhurima Basak., et al. "A Rapid and Sensitive RP-HPLC method for the Quantitative Analysis of Empagliflozin in bulk and Pharmaceutical Dosage Form". International Journal of Applied Pharmaceutics 11.5 (2019): 60-65.

8. Sushil D., et al. "Development and Validation of Stability Indicating RP-HPLC Method for Empagliflozin". Asian Journal of Pharmaceutical Analysis 6.4 (2016): 201-206.

9. Vinay Kumar D and JVLN Seshagiri Rao. "A New Validated Stability Indicating RP-HPLC Method for Simultaneous Estimation of Metformin Hydrochloride and Empagliflozin in Tablet Dosage Forms". International Research Journal of Pharmacy and Medical Sciences 1.5 (2018): 16-22.

10. Syed Irfan Ali and Bharath Rathna Kumar P. "Stability Indicating Simultaneous Estimation of Metformin and Empagliflozin in Pharmaceutical Tablet Dosage form by RP-HPLC". Asian Journal of Research in Chemistry 10.6 (2017): 783-788.

11. Nachiket S Dighe., et al. "Simultaneous Estimation, Validation and Force Degradation Study of Metformin Hydrochloride and Empagliflozin by RP-HPLC Method". Research Journal of Science and Technology 11.2 (2019): 135-147.

12. Sharmila Donepudi and Suneetha Achanta. "Validated HPLCUV method for simultaneous estimation of Linagliptin and Empagliflozin in human plasma". International Journal of Applied Pharmaceutics 10.3 (2018): 56-61.

13. Nagunath Sirigiri., et al. "Stability indicating method development and validation for simultaneous Estimation of Linagliptin and Empagliflozin in tablets by HPLC". Saudi Journal of Medical and Pharmaceutical Sciences 4.8 (2018): 884-896.

14. Wael Abu Dayyih., et al. "Development and Validation of a Stability-Indicating HPLC Method for Empagliflozin and Lina- gliptin in Tablet Dosage Form". Asian Journal of Chemistry 33.2 (2021): 484-488.

15. T Naga Ravi Kiran., et al. "Development and Validation of RPHPLC Method for the Simultaneous Estimation of Linagliptin, Empagliflozin and Metformin in Solid Dosage Forms". Asian Journal of Pharmaceutical Analysis 10.3 (2020): 117-124.

16. RP Bhole., et al. "Stability Indicating HPTLC Method for Simultaneous Estimation of Empagliflozin and Linagliptin in Pharmaceutical Formulation". Analytical Chemistry Letters 7.1 (2017): 76-85.

17. Bassam M Ayoub and Shereen Mowaka. "LC-MS/MS Determination of Empagliflozin and Metformin". Journal of Chromatographic Science 55.7 (2017): 742-747.

18. Mohamed Rizk., et al. "Thermo analytical study and purity determination of Anti-diabetic drugs Linagliptin and Empagliflozin in drug substances". Chemistry Research Journal 5.4 (2020): 6-20.

19. Shaik Bima Benazir., et al. "Method Development and Validation of Empagliflozin in Bulk and Pharmaceutical Dosage Form using UV Spectroscopy". Asian Journal of Pharmaceutical Analysis 11.2 (2021): 123-126.

20. Sushil D Patil., et al. "Development and Validation of Simple UV- Spectrophotometric Method for the Determination of Empagliflozin". Asian Journal of Pharmaceutical Analysis 7.1 (2017): 18-22.

21. Sushil D Patil., et al. "Development and validation of UV spectrophotometric method for Simultaneous estimation of Empagliflozin and Metformin hydrochloride in bulk drugs". Asian Journal of Pharmaceutical Analysis 7.2 (2017): 117-123.

22. Sushil D Patil., et al. "Spectrophotometric simultaneous determination of Empagliflozin and Metformin in combined tablet dosage form by absorbance corrected method, area under curve method, and dual wavelength spectrophotometry". Asian Journal of Research in Chemistry 12 .2 (2019): 94-98.

23. Manojkumar K., et al. "Development and Validation of Novel Analytical Method for Empagliflozin and Metformin Hydrochloride in Bulk and Pharmaceutical Dosage Form by Four Different Simultaneous Estimation Approaches using UV

Citation: Arulselvan Murugesan and Annapurna Mukthinuthalapati Mathrusri. “Novel Simplified Analytical Method for Stress Degradation Study of Empagliflozin an Oral Anti-diabetic Agent by RP-HPLC Method". Acta Scientific Pharmaceutical Sciences 6.1 (2022): 59-66. 
Spectroscopy". Research Journal of Pharmacy and Technology 13.3 (2020): 1236-1242.

24. Mokhtar M Mabrouk., et al. "Ultrasound-assisted dispersive liquid-liquid microextraction for determination of three gliflozins in human plasma by HPLC/DAD". Journal of Chromatography B 1136 (2019): 121932.

25. ICH guideline Q1A (R2). "Stability testing of new drug substances and products". ICH (2003).

26. ICH guideline Q2 (R1). "Validation of Analytical Procedures: Text and Methodology". ICH (2005).

\section{Assets from publication with us}

- Prompt Acknowledgement after receiving the article

- Thorough Double blinded peer review

- Rapid Publication

- Issue of Publication Certificate

- High visibility of your Published work

Website: www.actascientific.com/

Submit Article: www.actascientific.com/submission.php

Email us: editor@actascientific.com

Contact us: +919182824667 